\title{
Mixing, heat fluxes and heat content evolution of the Arctic Ocean mixed layer
}

\author{
A. Sirevaag ${ }^{1}$, S. de la Rosa ${ }^{1}$, I. Fer ${ }^{1}$, M. Nicolaus ${ }^{2,3}$, M. Tjernström ${ }^{4}$, and M. G. McPhee ${ }^{5}$ \\ ${ }^{1}$ Geophysical Institute, University of Bergen and Bjerknes Centre for Climate Research, Norway \\ ${ }^{2}$ Alfred Wegener Institute for Polar and Marine Research, Bremerhaven, Germany \\ ${ }^{3}$ Norwegian Polar Institute, Troms $\varnothing$, Norway \\ ${ }^{4}$ Department of Meteorology, Stockholm University, Sweden \\ ${ }^{5}$ McPhee Research Company, Naches WA, USA
}

Received: 6 January 2011 - Published in Ocean Sci. Discuss.: 1 February 2011

Revised: 2 May 2011 - Accepted: 4 May 2011 - Published: 18 May 2011

\begin{abstract}
A comprehensive measurement program was conducted during 16 days of a 3 week long ice pack drift, from 15 August to 1 September 2008 in the central Amundsen Basin, Arctic Ocean. The data, sampled as part of the Arctic Summer Cloud Ocean Study (ASCOS), included upper ocean stratification, mixing and heat transfer as well as transmittance solar radiation through the ice. The observations give insight into the evolution of the upper layers of the Arctic Ocean in the transition period from melting to freezing. The ocean mixed layer was found to be heated from above and, for summer conditions, the net heat flux through the ice accounted for $22 \%$ of the observed change in mixed layer heat content. Heat was mixed downward within the mixed layer and a small, downward heat flux across the base of the mixed layer accounted for the accumulated heat in the upper cold halocline during the melting season. On average, the ocean mixed layer was cooled by an ocean heat flux at the ice/ocean interface $\left(1.2 \mathrm{~W} \mathrm{~m}^{-2}\right)$ and heated by solar radiation through the ice $\left(-2.6 \mathrm{~W} \mathrm{~m}^{-2}\right)$. An abrupt change in surface conditions halfway into the drift due to freezing and snowfall showed distinct signatures in the data set and allowed for inferences and comparisons to be made for cases of contrasting forcing conditions. Transmittance of solar radiation was reduced by $59 \%$ in the latter period. From hydrographic observations obtained earlier in the melting season, in the same region, we infer a total fresh water equivalent of $3.3 \mathrm{~m}$ accumulated in the upper ocean, which together with the observed saltier winter mixed layer indicates a transition towards a more seasonal ice cover in the Arctic.
\end{abstract}

Correspondence to: A. Sirevaag (anders.sirevaag@bjerknes.uib.no)

\section{Introduction}

The Arctic plays an important role in the global climate system; it is home to key processes for ocean-atmosphere exchange and water mass modification, and it is a strong indicator of the global climate change, as atmospheric temperature changes are amplified in the Arctic (Screen and Simmonds, 2010; Serreze et al., 2009). Since the late 1970's, the atmospheric warming of the Arctic (Comiso, 2003) has been accompanied by a warming of the Arctic Ocean (Grotefendt et al., 1998) and a decrease in both sea ice extent (Comiso et al., 2008; Parkinson and Cavalieri, 2008; Stroeve et al., 2008) and thickness (Maslanik et al., 2007; Kwok and Rothrock, 2009; Haas et al., 2008). In the same period, the salinity content of the Arctic shelves and the Canadian basin has decreased as opposed to an increase in the Eurasian basin (McPhee et al., 2009; Polyakov et al., 2008). Due to an earlier onset of melting and later onset of freezing, the melting season in the central Arctic has increased by 10 days since 1979 (Markus et al., 2009), which reflects a shift towards a more seasonal ice cover (Kinnard et al., 2008; Maslanik et al., 2007; Nghiem et al., 2007). The observed changes in ice cover exposes the Arctic Ocean to a more direct exchange with the atmosphere and allows for new processes of upper ocean-atmosphere exchange to take place, such as e.g. windinduced mixing (Rainville and Woodgate, 2009). A shift towards a more seasonal Arctic sea ice cover also have strong implications for maintaining the marine biological life, as biological productivity is maintained through the provision of nutrients by upwelling and eddies in the expanding open water areas (Niebauer and Alexander, 1985).

Published by Copernicus Publications on behalf of the European Geosciences Union. 
The central Arctic basin can be separated, on the basis of temperature and salinity characteristics of the water, into a vertical layered system. A relatively fresh and isothermal surface mixed layer with temperatures close to freezing is due in part to continental river runoff, inflow of low salinity Pacific Water through the Bering Strait and penetrative convection in winter followed by melting in summer (Rudels et al., 1996; Aagaard et al., 1981).

The surface mixed layer resides above a layer with low temperatures and a distinct salinity gradient, the so called cold halocline layer (Aagaard et al., 1981), which, due to its strong stratification, forms an efficient barrier between the surface mixed layer and the relatively warm and salty water residing below. This water originates from the flow of Atlantic Water through the Fram Strait and is gradually modified by atmospheric cooling, sea ice melting during summer (Sirevaag and Fer, 2009) and mixing as it flows northward along the western coast of Spitsbergen and eastward along the continental shelf of the Arctic basin. The depth of the core of AW gradually increases as the water circulates along the margins and into the deep basins of the Arctic (Dmitrenko et al., 2008) and in the Amundsen Basin, close to the North Pole, the core of the AW derived water resides at around $300 \mathrm{~m}$ depth.

The Arctic Ocean mixed layer undergoes a distinct seasonal cycle (Rudels et al., 1996). Atmospheric winter cooling and subsequent ice formation lead to a colder, saltier and deeper mixed layer, whereas ice melting and atmospheric heating of the mixed layer during summer lead to a fresher and shallower, but also slightly warmer, mixed layer. Solar radiation is the most important source of heat for the ocean mixed layer (Maykut and McPhee, 1995; Perovich, 2005), mostly through leads and open water areas, but transmittance of solar radiation through melt ponds also provides a significant amount of heat to the mixed layer (Inoue et al., 2008; Itoh et al., 2011). Inflow of warm, low salinity Pacific Water through the Bering Strait is also a direct source of heat for the ocean mixed layer (Alkire et al., 2007; Woodgate et al., 2010). Transfer of heat from the deep, Atlantic derived water is limited by the stratification in the cold halocline layer and is found to be negligible for the Amundsen Basin (Fer, 2009) and on average $0.3-1.2 \mathrm{~W} \mathrm{~m}^{-2}$ for the for the Canadian Basin (Shaw et al., 2009), hence the most efficient heat loss from the AW occurs along the continental shelves, but not in the central Arctic (e.g. Padman, 1995; Rudels et al., 2000).

The upward transfer of heat towards the ice/ocean interface, the surface ocean heat flux is in general determined by the amount of heat and turbulent mixing in the surface mixed layer. Maykut and Untersteiner (1971) found, by invoking a 1-D thermodynamic sea ice model, that a surface ocean heat flux of $2 \mathrm{~W} \mathrm{~m}^{-2}$ was necessary to reach an equilibrium ice thickness similar to the typical observed thickness. Later observations have revealed the heat flux to be larger; $5.1 \mathrm{~W} \mathrm{~m}^{-2}$ for the Canadian Basin (Maykut and McPhee, 1995) and

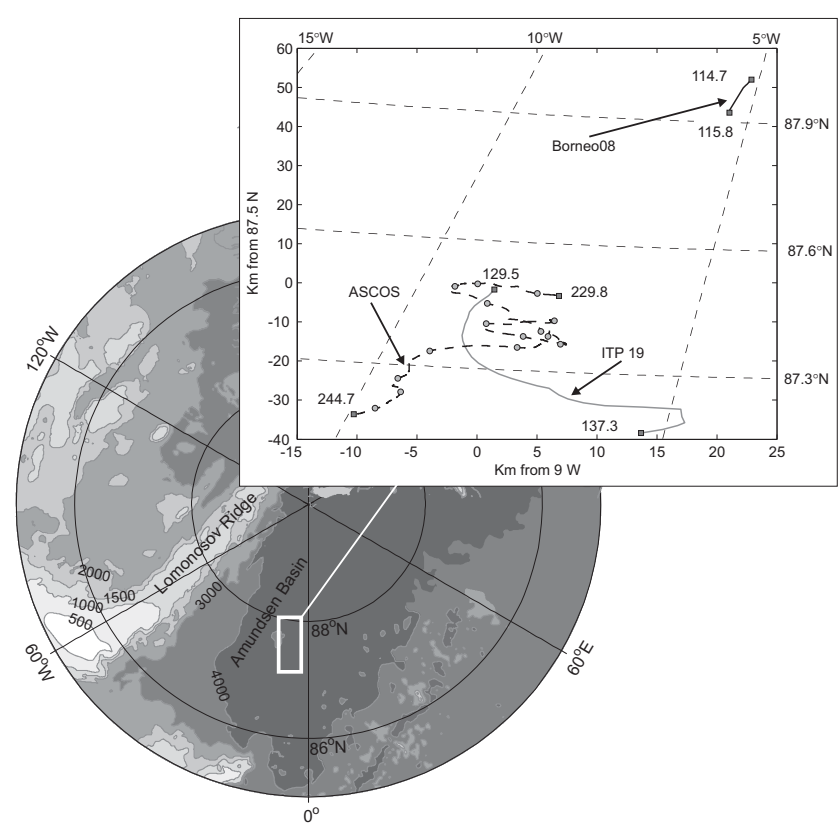

Fig. 1. The drift trajectory of the ASCOS field experiment, the Borneo08 experiment and the ITP19 drifting buoy. The map with bathymetric depth contours outlined, shows the study region location.

$\sim 3.5 \mathrm{~W} \mathrm{~m}^{-2}$ for the entire Arctic basin (Krishfield and Perovich, 2005), although fluxes up to an order of magnitude larger have been measured towards the end of the melting season, during instances of maximum mixed layer heat content (Maykut and McPhee, 1995).

\subsection{Arctic Summer Cloud Ocean Study}

The Arctic Summer Cloud Ocean Study (ASCOS) was a multidisciplinary International Polar Year (IPY) project with the aim of studying the formation of Arctic low level clouds and their role for the surface energy balance, impacts on the melting and freezing of the sea ice covered Arctic Ocean and with linkages to microbiological life in the open ocean and ice. The project was organized with research groups within meteorology, physical oceanography, atmospheric gas and particulate phase chemistry, aerosol physics and marine biology, as an expedition based onboard the Swedish research ice breaker Oden towards the end of summer and start of the freezing season (2 August-9 September) in 2008. While a few shorter stations were made south of the ice edge and in the marginal ice zone during the transit to the high Arctic, the focus of the project was the setup of an ice-drift station, centred at $87.4^{\circ} \mathrm{N}$ and $6^{\circ} \mathrm{W}$, running from 12 August to 1 September (Fig. 1). During this period, Oden was moored to an approximately $6 \times 3 \mathrm{~km}$ ice floe (Fig. 2), which drifted west, south-westward with an average speed of $9 \mathrm{~cm} \mathrm{~s}^{-1}$ over a total distance of $157 \mathrm{~km}$. 


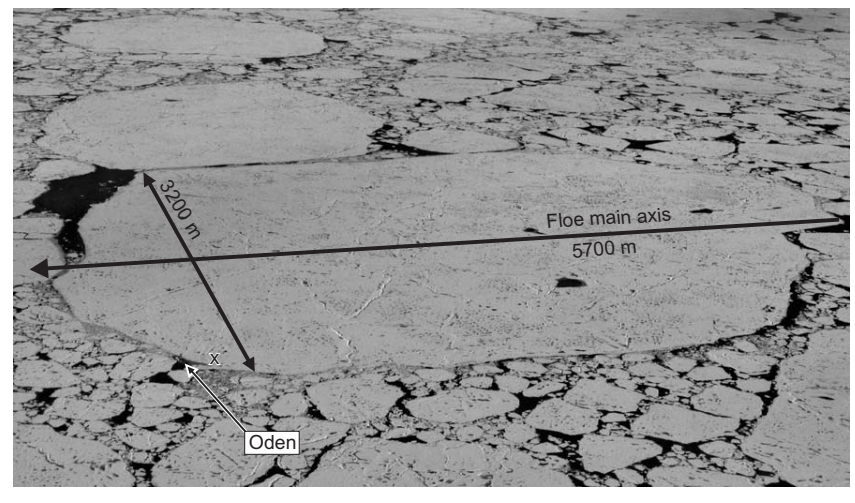

Fig. 2. The ASCOS experiment floe photographed from helicopter. Length and width are estimated from mapping of ice floe from helicopter. The orientation of the floe's main axis is calculated from simultaneous GPS measurements at the ship and on the floe. The cross indicates the site of the ocean measurements.

In the pristine Arctic environment, a passive ice drift was a necessary condition for gases and aerosol particles to be sampled with minimum interference from the ship and immediate surroundings. The ice drift also enabled deployment of instruments for atmospheric and oceanographic boundary layer studies on the ice sufficiently far away, $150 \mathrm{~m}-450 \mathrm{~m}$ from Oden, to avoid disturbances from the ship's hull and superstructure and still within reach of continuous power supply from the ship.

\subsection{Environmental conditions}

Selected environmental parameters are plotted in Fig. 3 for the observation period. Average air temperature was $-2.6^{\circ} \mathrm{C}$ (Fig. 3a). A short period with temperatures below $-5^{\circ} \mathrm{C}$ occurred between doy 234 and 237 (throughout this paper, time is given as decimal day of year (doy) in 2008, where doy 229.75 equals 16 August 2008 18:00 UTC). This period is referred to as the "cold snap" (Sedlar et al., 2010), when a drop in temperature caused the surface to freeze, including most of the melt ponds and open water areas. This temperature drop of $5^{\circ} \mathrm{C}$ in $21 \mathrm{~h}$ was followed by a strong snowfall during the second half of doy 236, which changed the surface conditions from summer-like to autumn-like conditions (see also Nicolaus et al., 2010b). In the following, doy 236.75 is considered the time of changing ice conditions.

The water temperature measured at $3.8 \mathrm{~m}$ depth varied within a narrow range between $-1.73^{\circ} \mathrm{C}$ and $-1.68^{\circ} \mathrm{C}$ (Fig. 3b) and was on average just $0.053^{\circ} \mathrm{C}$ above the local freezing temperature. Salinity is calculated using the practical salinity scale throughout.

Over the observation period considered here (doy 229.75 to doy 244.75), the ice floe drifted slowly south-westward with an average speed of $6.7 \mathrm{~cm} \mathrm{~s}^{-1}$, covering a total distance of $87.1 \mathrm{~km}$ (Fig. 1). Winds were in general calm with an average speed of $3.4 \mathrm{~m} \mathrm{~s}^{-1}$ with no distinct prevailing wind direction (Fig. 3c).
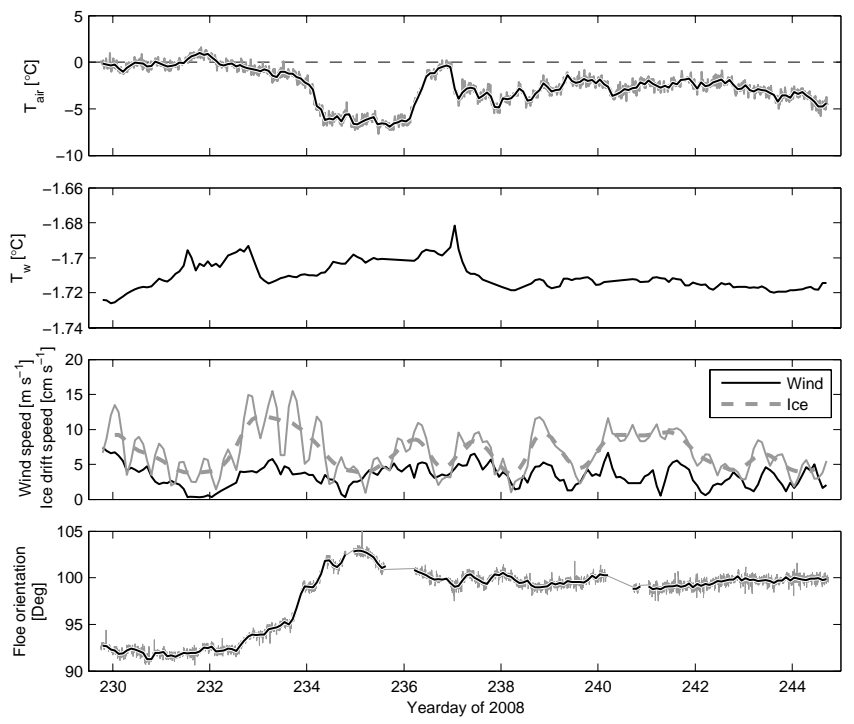

Fig. 3. Time series of (a) air temperature at $21 \mathrm{~m}$ height, (b) water temperature at $3.8 \mathrm{~m}$ depth, (c) wind speed (in $\mathrm{m} \mathrm{s}^{-1}$ ), ice drift speed (in $\mathrm{cm} \mathrm{s}^{-1}$ ) and (d) orientation of the floe's main axis (see location of axis in Fig. 2).

On average, the drift speed was $2 \%$ of the wind speed and followed the same variability. The ice drift speed also showed variability on a shorter time scale (Fig. 3c) due to inertial oscillations (inertial period at $87.5^{\circ} \mathrm{N}=12 \mathrm{~h}$ ) or a diurnal tidal flow. Despite the drift distance and the inertial oscillations shown in the drift trajectory during the experiment, the ice floe maintained a constant orientation to within $\pm 5^{\circ}$.

Ice thickness in the vicinity of the ocean and radiation measurement site varied from $1.5 \mathrm{~m}$ to more than $3 \mathrm{~m}$. Early into the drift, the ice surface was covered by typical $10 \mathrm{~cm}$ of snow and numerous open melt ponds with a significant spatial variation. Several short duration snowfalls and periods with deposition of rime on the surface changed the surface conditions throughout the drift (see Fig. 11 of Nicolaus et al., 2010b).

This paper presents and discusses the upper ocean measurements obtained during the ASCOS ice drift in the Amundsen Basin. Transmission of solar radiation through the ice and the evolution of the Arctic Ocean mixed layer are described during the transition from melting to freezing. Results are compared to data obtained in the same area in late April and mid May. Measurement systems, basic processing routines and methods are presented in the next section and the upper ocean stratification and the vertical heat fluxes are presented in Sect. 3. The seasonal development of the upper ocean, the energy balances for the ice/ocean interface, mixed layer and across the base of the mixed layer and the variability of heat content and heat fluxes are presented and discussed in Sect. 4 and a summary is given in Sect. 5. 


\section{Measurements, data and data processing}

Upper ocean measurements were carried out continuously, using a tethered free-falling microstructure turbulence profiler (Sect. 2.1) and eddy covariance instruments suspended in the boundary layer beneath the sea ice (Sect. 2.2). Ocean sampling was made, together with spectral albedo and transmittance measurements (Sect. 2.3), about $160 \mathrm{~m}$ away from the ship. Ancillary data include shipboard wind and air temperature measurements and GPS position data from the ship and the ice. The latter were used together to obtain the rotation of the ice floe during the drift. Ocean measurements started regularly from doy 229.75 and the measurement period reported here was from doy 229.75 to doy 244.75.

Additionally, we use data from the same region, collected in late April and mid-May 2008, to compare the mean properties of the upper ocean during the ASCOS drift with late winter and spring conditions. Profiles in late April 2008 were collected from the drifting ice camp Borneo, and those in late spring were from the drifting Ice Tethered Platform No. 19 (ITP 19, data made available through Woods Hole Oceanographic Institution, http://www.whoi.edu/itp). From the Borneo experiment, 10 profiles collected between doy 114.7 to doy 115.8 were averaged and referred to as Borneo08 throughout this paper. The drift trajectory of the ITP19 was compared to the ASCOS drift trajectory and 31 profiles from the period doy 129.5-137.3, when ITP19 drifted through the ASCOS area, were averaged.

\subsection{Microstructure profiling}

The microstructure profiling was performed using a MSS90 (ISW Wassermesstechnik, Germany), a loosely tethered free-fall profiler equipped with precision conductivity, temperature, depth (CTD) sensors and a suite of turbulence sensors including two airfoil shear probes, a fast-response thermistor FP07 and a micro conductivity sensor (Fer, 2006; Fer and Sundfjord, 2007). The profiler (MSS hereafter) was deployed through the ice with a motorized winch and profiles were made hourly from the underside of the ice at $2 \mathrm{~m}$ depth and down to $500 \mathrm{~m}$. In total 345 profiles were obtained during the ASCOS ice drift.

Microstructure data processing is briefly described here and in more detail in Fer (2006). All channels of the profiler sampled at $1024 \mathrm{~Hz}$ and were averaged to $256 \mathrm{~Hz}$ to reduce noise. The viscous dissipation rate of turbulent kinetic energy per unit mass, $\varepsilon\left(\mathrm{W} \mathrm{kg}^{-1}\right)$, was calculated using the isotropic relation $\varepsilon=7.5 v\left\langle u_{z}^{\prime 2}\right\rangle$, where $v$ of sea water, $\left\langle u_{z}^{\prime 2}\right\rangle$ is the shear variance of horizontal small scale velocity and brackets indicate averaging. The shear variance was obtained by integrating the wave number spectrum from 1-s long segments. The instrument fall speed $\left(\sim 0.7 \mathrm{~m} \mathrm{~s}^{-1}\right)$ was used to convert data from the frequency domain to the wave number domain using Taylor's hypothesis. Dissipation data in the upper $5 \mathrm{~m}$ was unreliable due to initial adjustment to free fall.
After the initial processing, CTD data and $\varepsilon$ were available as 10 and $50 \mathrm{~cm}$ vertical averages, respectively.

The eddy diffusivity for mass was calculated as, $K_{\rho}=0.2 \varepsilon / N^{2}$ (Osborn, 1980) using the buoyancy frequency, $N$, from sorted $\sigma_{\theta}$ profiles. The eddy diffusivity for heat was calculated using $K_{T}=3 k_{T} C x$ (Osborn and Cox, 1972), where $k_{T}=1.4 \times 10^{-7} \mathrm{~m}^{2} \mathrm{~s}^{-1}$ is the molecular diffusivity for heat and $C x=\left\langle\left(\partial T^{\prime} / \partial t\right)^{2}\right\rangle /\left\langle(\partial T / \partial z)^{2}\right\rangle$ is the Cox number. $\langle\partial T / \partial z\rangle$ is the background temperature gradient over the vertical depth segment in consideration and $\left\langle\left(\partial T^{\prime} / \partial t\right)^{2}\right\rangle$ is the small scale temperature gradient variance. The latter is not resolved to dissipative scales, and was instead inferred from the dissipation rate of thermal variance, $\chi=2 k_{T}\left\langle 3\left(\partial T^{\prime} / \partial z\right)^{2}\right\rangle$ by fitting the universal Batchelor form (Dillon and Caldwell, 1980) to the temperature gradient spectrum in the resolved wave number band. The fit was constrained by the measured $\varepsilon$ within the vertical segment.

Vertical heat fluxes from the microstructure profiles were calculated as

$F_{H}=-\rho c_{p} K_{T} \partial T / \partial z$

where $\rho$ is the density and $c_{p}$ is the specific heat within each vertical depth segment. Initially, the water column was divided into 4-m vertical segments. However, to ensure a higher vertical resolution and resolve the heat fluxes across the base of the mixed layer (Sect. 2.4), the $4 \mathrm{~m}$ layer above the base of the mixed layer was divided into 2-m vertical segments and the $4 \mathrm{~m}$ layer below the base of the mixed layer was divided into $1-\mathrm{m}$ vertical segments.

\subsection{Turbulence instrument clusters}

In order to measure ocean properties and vertical fluxes of heat, salt and momentum close to the ice-ocean interface, a mast containing three Turbulence Instrument Clusters (TICs, McPhee, 2008) was deployed through a hole in the $1.8 \mathrm{~m}$ thick sea ice. Each TIC comprised a $5 \mathrm{MHz}$ Acoustic Doppler Velocimeter (ADVOcean, Sontek/YSI, USA) which measured the 3-D velocity in a small volume and fast response temperature (SBE3, SeaBird Electronics, USA) and conductivity (SBE7) sensors. All sensors were aligned at the same vertical level to make covariance estimates. In addition, a ducted conductivity sensor (SBE4) was mounted roughly $20 \mathrm{~cm}$ above the others to make accurate measurements of the absolute conductivity.

The turbulence mast was fixed to the ice with TICs at $2 \mathrm{~m}$, $6 \mathrm{~m}$ and $7.8 \mathrm{~m}$ below the ice, i.e. at $3.8 \mathrm{~m}, 7.8 \mathrm{~m}$ and $9.6 \mathrm{~m}$ depth and the mast was oriented with sensors directed towards the mean current in the under-ice boundary layer. In this study, heat fluxes at the ice/ocean interface will be the main focus; hence we will focus mainly on measurements from the TIC at $3.8 \mathrm{~m}$ depth, however some results from the TIC at $7.8 \mathrm{~m}$ depth are included in order to show consistency of the measurements in the surface layer. 
Velocity, temperature and salinity data were measured at $2 \mathrm{~Hz}$ and binned into 15-min intervals in order to capture the covariance in the turbulent eddies and avoid energy input from processes on larger time scales (McPhee, 2008). 3-D velocity $U$ was rotated into a streamline coordinate system such that $\langle u\rangle=|\bar{U}|$ and $\langle v\rangle=\langle w\rangle=0$. Deviatory velocities, temperatures and salinities were found by removing the linear trend within each averaging interval. Vertical turbulent surface heat flux and the kinematic friction velocity were calculated as

$$
\begin{aligned}
& F_{H 0}=\rho c_{p}\left\langle w^{\prime} T^{\prime}\right\rangle \\
& u_{*}=\left(\left\langle u^{\prime} v^{\prime}\right\rangle^{2}+\left\langle u^{\prime} w^{\prime}\right\rangle^{2}\right)^{1 / 4}
\end{aligned}
$$

where $\rho$ is the seawater density and $c_{p}$ is the specific heat of seawater. Kinematic friction velocity is related to the stress, $\tau$, as $u_{*}=\sqrt{\tau / \rho}$.

For the TIC at $7.8 \mathrm{~m}$, heat fluxes were calculated from the $w^{\prime} T^{\prime}$ covariance, as described above. Friction velocities were calculated using a spectral method following McPhee (2004) and the dissipation rate of turbulent kinetic energy was calculated by evaluating the spectra of vertical velocity (e.g. McPhee, 2008).

\subsection{Spectral albedo and transmittance measurements}

Spectral albedo and transmittance were measured with RAMSES ACC (Trios GmbH, Oldenburg, Germany) radiometers, as described in Nicolaus et al. (2010b). Two sensors were installed above the surface for albedo measurements, one downward-looking and another upwardlooking. For transmittance measurements, an additional upward-looking sensor was used and installed $1.0 \mathrm{~m}$ under the sea ice. Initial ice thickness, snow thickness, and freeboard at the optical measurement site were $1.54 \mathrm{~m}, 0.10 \mathrm{~m}$, and $0.05 \mathrm{~m}$, respectively. Continuous measurements started on doy 228.6 and 10-min average spectra were measured until doy 245.4 for albedo data and until doy 244.8 for transmittance data. The shorter time span of transmittance measurements was due to the more time-consuming retrieval of the under-ice sensor. In total, 2410 albedo and 2325 transmittance spectra were recorded. All measurements were performed during polar day with solar elevation angles (elevation angle $=90^{\circ}-$ zenith angle) between $5.5^{\circ}$ and $16.1^{\circ}$. The site was visited daily to check for levelling of the station and condensation or icing on the sensors. Presented data were corrected for shadow effects on the sensors as described in Nicolaus et al. (2010b), where also the entire data set is discussed.

Manual measurements of snow and ice temperatures, snow thickness and texture were made every 3 days and observations of precipitation and changes in surface conditions were made daily at the optical measurement site, to document snow and sea-ice conditions and their changes.

\subsection{Mixed layer properties}

Vertical profiles of potential density were used to calculate the depth of the base of the mixed layer, $D_{\mathrm{ml}}$ as the depth at which the density increases by $20 \%$ of the mean density of the upper $10 \mathrm{~m}$ (e.g. Shaw et al., 2009). By using summer profiles, the depth of the winter mixed layer, $D_{\mathrm{wml}}$, can be estimated as the depth of the temperature minimum (Rudels et al., 1996). The corresponding salinity of the winter mixed layer, $S_{\mathrm{wml}}$, is the salinity at the depth of minimum $T$. The fresh water content in the upper ocean was calculated as

$\mathrm{FWC}=\frac{\left(D_{\mathrm{wml}} S_{\mathrm{wml}}-\int S(z) d z\right)}{S_{\mathrm{wml}}}$

where the integral was obtained by a summation of salinities above $D_{\text {wml }}$.

From profiles of temperature and salinity, the heat content at a given depth was determined as

$H(z)=\left(T(z)-T_{f}(z)\right) \rho(z) c_{p}(z)$

where $T_{f}, \rho$ and $c_{\mathrm{p}}$ are freezing temperature, density and specific heat, respectively, as a function of salinity and given depth. Total amount of sensible heat in any given layer was calculated as

$$
H_{\text {layer }}=\int_{D_{\text {layer }}}^{0} H(z) d z
$$

where $D_{\text {layer }}$ is the layer depth.

\section{Results}

\subsection{Upper ocean stratification}

Average profiles of temperature, salinity and density for the first $24 \mathrm{~h}$ of the experiment are shown for the upper $500 \mathrm{~m}$ in Fig. 4. Averaging filters out the variability on the semidiurnal/inertial time scale and the temporal variability in the mixed layer over the entire experiment length. Profiles show a $28 \mathrm{~m}$ deep, well mixed upper layer with average temperature of $-1.72{ }^{\circ} \mathrm{C}$ and salinity of 32.31 . Below this mixed layer was a uniform cold layer with a strong salinity gradient, which was the remnant of the previous winter's mixed layer (e.g. Rudels et al., 1996) and which formed the upper cold halocline layer. The cold halocline layer extended down to around $100 \mathrm{~m}$ depth, from where the temperature increase made the density increase smaller. The temperature minimum $\left(T=-1.80^{\circ} \mathrm{C}\right)$ at $67 \mathrm{~m}$ represented the base of the winter mixed layer, $D_{\mathrm{wml}}$, and for the remainder of this paper, the upper cold halocline layer refers to the part of the cold halocline that resides above $D_{\mathrm{wml}}$. Salinity at $D_{\mathrm{wml}}$ was 33.11, representative of the winter mixed layer salinity, $S_{\mathrm{wml}}$. The Borneo08 profile represents the actual winter conditions in the area and had an average mixed layer salinity of 33.16 , 


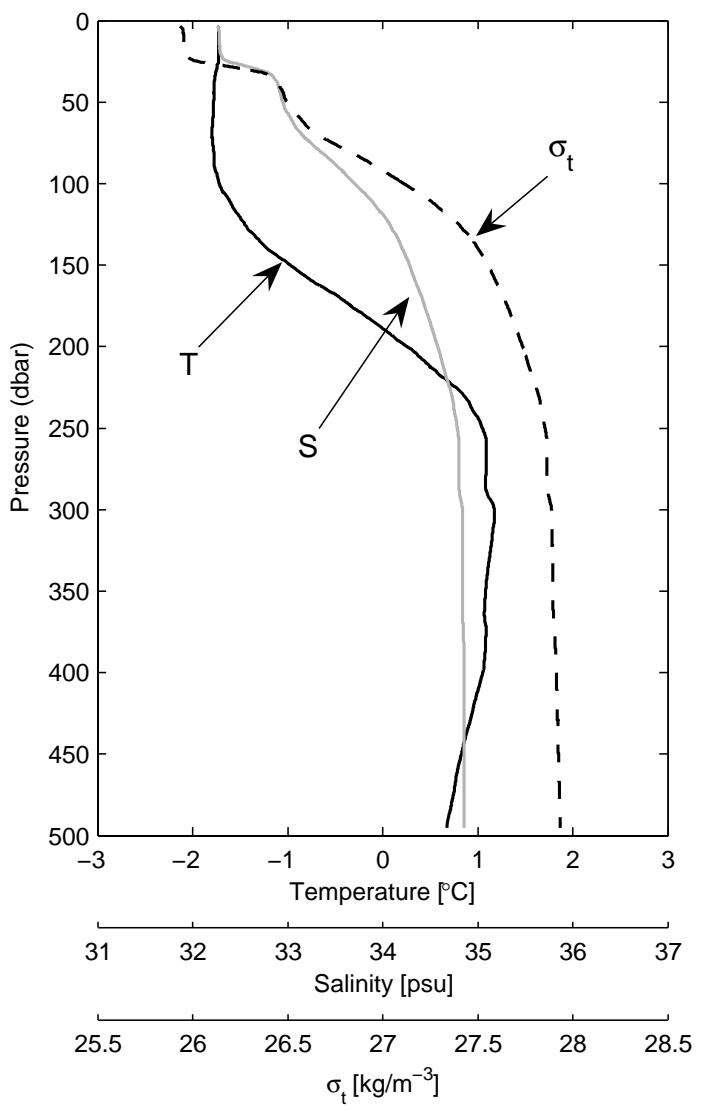

Fig. 4. Temperature, salinity and potential density averaged over the first $24 \mathrm{~h}$ (7 profiles) of the ASCOS experiment.

which was only slightly saltier then $S_{\mathrm{wml}}$ estimated from the ASCOS profiles. This lends confidence to the approximation by Rudels et al. (1996), and throughout the rest of the paper, the measured value of $S_{\mathrm{wml}}=33.16$ will be used. A temperature maximum of $1.18^{\circ} \mathrm{C}$ (and corresponding salinity of 34.84) was found at $304 \mathrm{~m}$, which was the depth of the core of the remaining AW that had deepened and cooled along the Arctic margin and towards the central Arctic (Dmitrenko et al., 2008).

The upper $100 \mathrm{~m}$ profiles of temperature and salinity from the start, middle and end of the ASCOS experiment were compared to the profiles collected in late April (Borneo08) and mid-May (ITP19) in Fig. 5. The late winter and spring profiles had deeper mixed layers with temperatures $\sim 0.1^{\circ} \mathrm{C}$ lower and salinities $\sim 0.75$ higher than the average ASCOS profiles. Although the onset of melting in the central Arctic in general occurs between doy 161 and doy 175 (Markus et al., 2009), the ITP19 buoy data indicate that there was a significant freshening of the mixed layer already around doy 133 compared to Borneo08 profiles on doy 114 .

During the ASCOS drift, a distinct heating of the upper metres was observed from the start to the middle of the experiment, with a temperature difference of $\sim 0.2^{\circ} \mathrm{C}$ (Fig. 5a). By the end of the experiment, the upper layer temperature
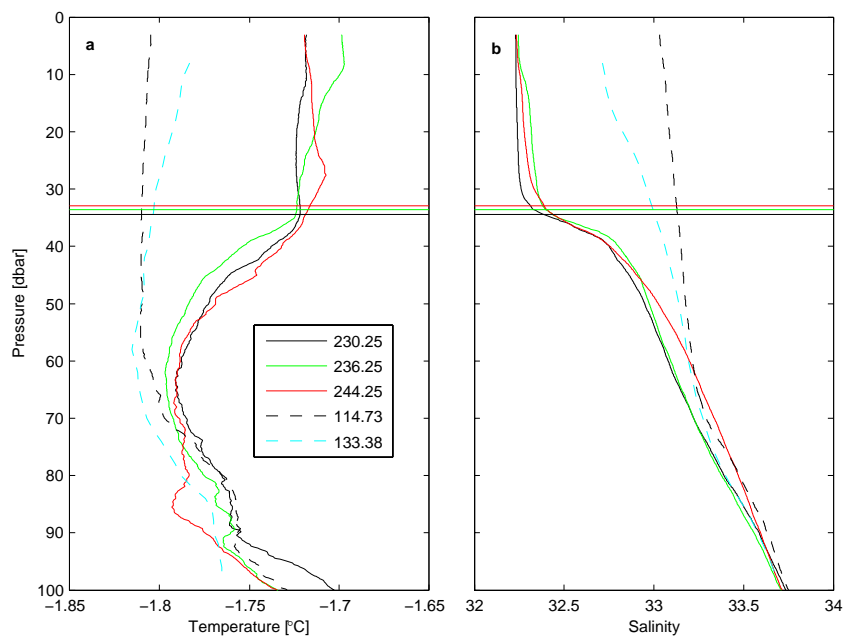

Fig. 5. Depth profiles (upper $100 \mathrm{~m}$ ) of (a) temperature and (b) salinity for the start, middle and end of the drift, for the end of the Borneo08 experiment (doy 114) and from the ITP19 profiling buoy (doy 133). ASCOS profiles are averaged over a 24-h period, centred at the time given in the legend. Barneo08 profiles are the averages of the 10 last profiles during the experiment and ITP19 profiles are the averages of all single profiles obtained within the latitude and longitude ranges defined by the ASCOS drift. Horizontal lines indicate the depth of the mixed layer for the average profiles.

was similar to that in the beginning of the drift, however, a similar heating was seen closer to the base of the mixed layer. Salinities in the upper $10 \mathrm{~m}$, on the other hand, were identical within the measurement uncertainty range. Differences in the mean salinity profiles below $10 \mathrm{~m}$ were most likely due to horizontal differences in salinity.

Fig. 6a shows the temperature and salinity contours of the upper $50 \mathrm{~m}$ during the experiment together with $D_{\mathrm{ml}}$. $D_{\mathrm{ml}}$ remained relatively constant, at an average of $34 \mathrm{~m}$, but with some shorter periods with significant lifting of the base of the mixed layer that led to a temporarily shallower mixed layer. Temperature contours show the same development in time as indicated in Fig. 5a, with a heating of the upper mixed layer during the first half of the experiment and a heating above $D_{\mathrm{ml}}$ during the second half. The mixed layer temperature maximum was mixed downward from the surface and towards the base of the mixed layer. This will be discussed further in Sect. 4.2.

\subsection{Vertical heat fluxes}

The basic features of the TIC measurements at $3.8 \mathrm{~m}$ depth are shown in Fig. 7. Mean characteristics within each $15 \mathrm{~min}$ interval were averaged in $3 \mathrm{~h}$ bins to remove some of the natural variability in the turbulent flow. Horizontal current velocities, relative to the ice, were in general small, on average $4.6 \mathrm{~cm} \mathrm{~s}^{-1}$ and varied between 2 and $10 \mathrm{~cm} \mathrm{~s}^{-1}$. Temperature elevation above the local freezing temperature varied from 

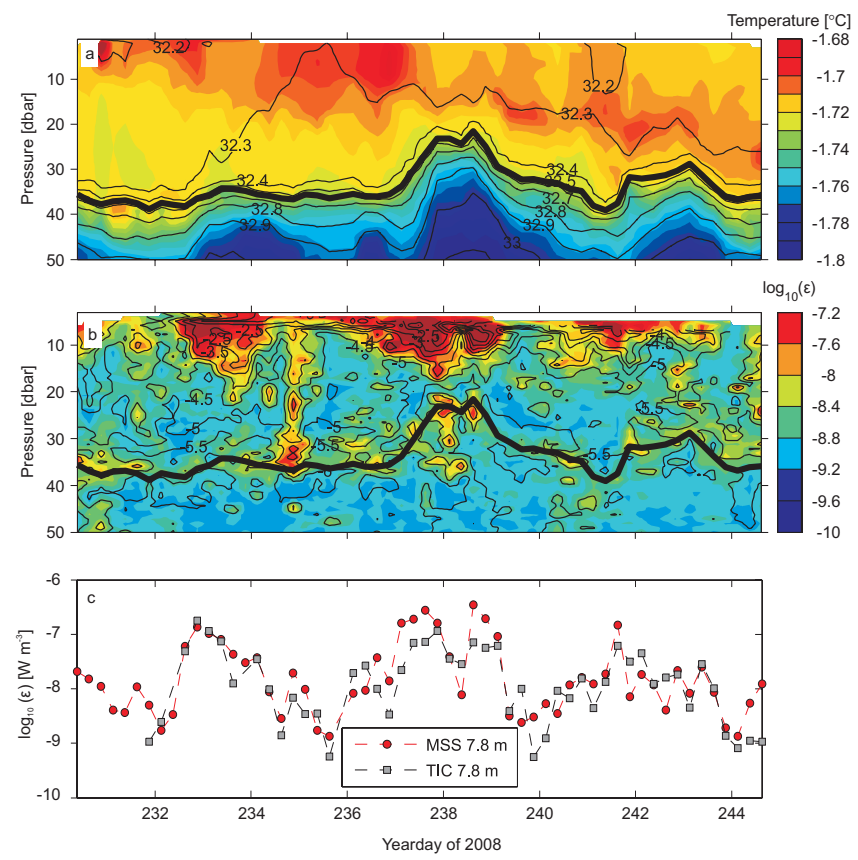

Fig. 6. Contour plot of (a) temperature (colour) and salinity (black) and (b) dissipation rate of turbulent kinetic energy, $\log _{10}(\varepsilon)$ (colour) and eddy diffusivity of mass, $\log _{10}\left(K_{\rho}\right)$ (black) for the upper $50 \mathrm{~m}$. Thick black line in both panels indicates the base of the mixed layer. (c) Dissipation rate of turbulent kinetic energy, $\log _{10}(\varepsilon)$, estimated from MSS and TIC at $7.8 \mathrm{~m}$ depth.

0.04 to $0.08^{\circ} \mathrm{C}$, with an average value of $0.053^{\circ} \mathrm{C}$, close to the average for the entire mixed layer. The turbulent stress is related to the velocity shear in the boundary layer and Fig. 7b shows that the friction velocity $\left(u_{*}\right)$ varied with the horizontal velocity and had an average value of $0.26 \mathrm{~cm} \mathrm{~s}^{-1}$. The friction velocity at $7.8 \mathrm{~m}$ followed the same variability as at $3.8 \mathrm{~m}$, but was slightly smaller in magnitude $\left(0.24 \mathrm{~cm} \mathrm{~s}^{-1}\right)$ as expected from the attenuation of stress in the surface layer.

The ocean surface heat flux was positive during most of the experiment, implying a heat flux from the ocean to the ice and was on average $1.2 \mathrm{~W} \mathrm{~m}^{-2}$, however it varied between 0 and $5 \mathrm{~W} \mathrm{~m}^{-2}$. Towards the end of the experiment it flattened out around zero, reflecting the slight decrease in temperature elevation above freezing and the low stress at the interface as shown by the friction velocities. At $7.8 \mathrm{~m}$ depth, heat fluxes were similar with an average value of $0.8 \mathrm{~W} \mathrm{~m}^{-2}$. Some of the difference between $3.8 \mathrm{~m}$ and $7.8 \mathrm{~m}$ must be attributed to the differences in data coverage for the two sensors for some periods.

Measurements of transmitted solar radiation showed a significant flux through the ice into the upper ocean (Fig. 8). There was a distinct daily variation in the flux, corresponding to the daily variation of the incoming solar radiation, and the transmitted solar irradiance ranged from -9 to $-1 \mathrm{Wm}^{-2}$ with an average of $-2.6 \mathrm{~W} \mathrm{~m}^{-2}$. The effect of the cold period, which was followed by a snowfall at doy 236.75 , was

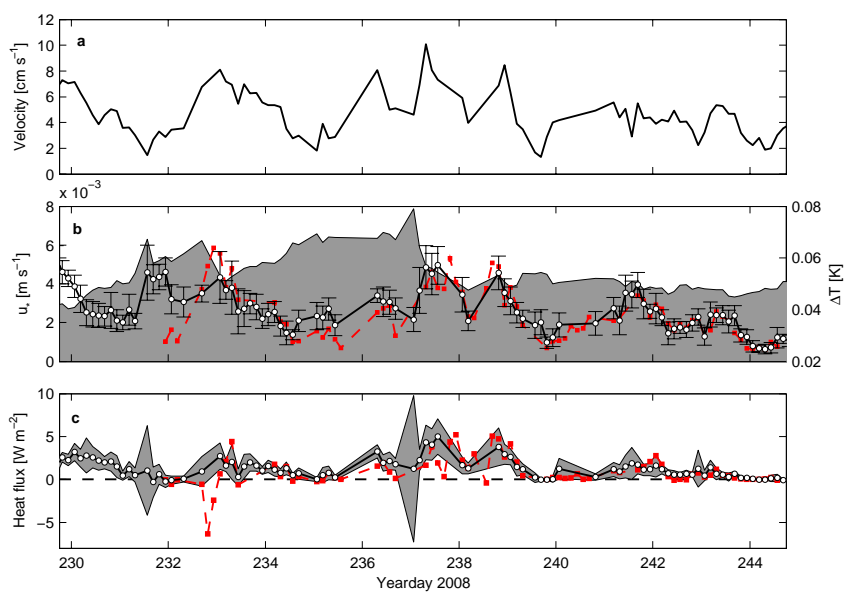

Fig. 7. Turbulence mast measurements at $3.8 \mathrm{~m}$ depth $(2 \mathrm{~m}$ below ice/ocean interface) averaged in 3-h intervals. Time series of (a) current speed relative to the ice, (b) friction velocity, $\mathrm{u}_{*}, \pm$ one standard deviation (circles and errorbars) and temperature elevation above freezing, $\Delta T$, (grey shading) and (c) ocean heat flux where grey shading indicates \pm one standard deviation. Red squares in (b) and (c) are friction velocities and heat fluxes from the TIC at $7.8 \mathrm{~m}$ depth, calculated as described in the text.

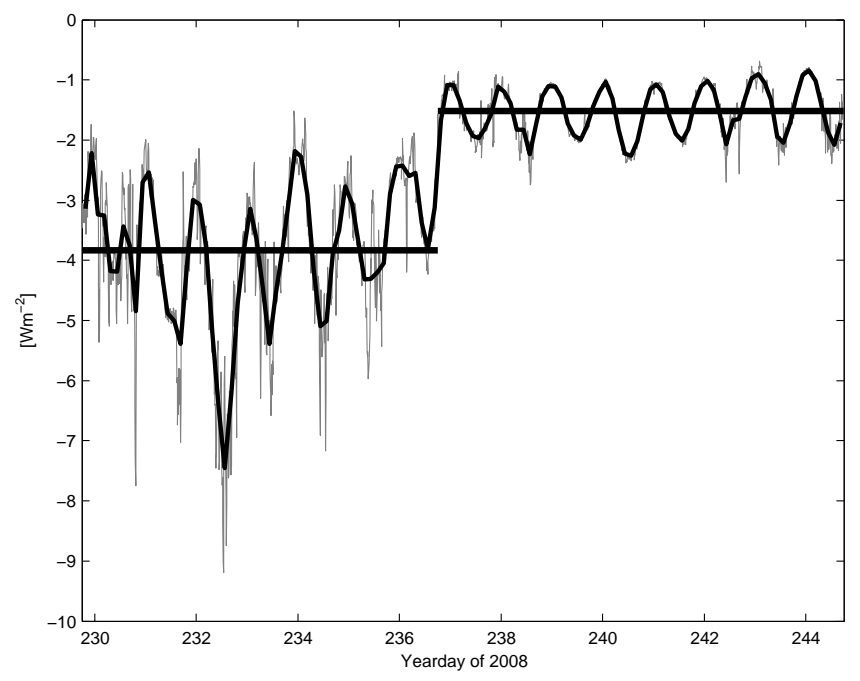

Fig. 8. Spectrally averaged transmitted solar irradiance below the sea-ice at the ocean measurements site. Black line is a 3-h running mean and horizontal lines indicate averages for periods before and after the change in surface conditions occurring on doy 236.75. Positive fluxes are upwards; hence negative fluxes represent an input of energy to the ocean mixed layer.

visible as a shift in the mean transmitted radiation, as well as a dampening of the daily variations (Time series of solar radiation and spectral albedo are presented in detail in Nicolaus et al., 2010b). Average flux into the ocean mixed layer was $-3.7 \mathrm{~W} \mathrm{~m}^{-2}$ before and $-1.5 \mathrm{~W} \mathrm{~m}^{-2}$ after the snowfall. 
For each MSS profile, the vertical heat flux within the mixed layer was obtained by averaging all 4-m depth bins from the surface and down to $4 \mathrm{~m}$ above the base of the mixed layer, $D_{\mathrm{ml}}$ (Fig. 9a). For each profile, the vertical heat flux across the base of the mixed layer was calculated as the average heat flux in the $8 \mathrm{~m}$ thick layer centred at $D_{\mathrm{ml}}$, which varied between $22 \mathrm{~m}$ and $39 \mathrm{~m}$ during the experiment. Depth averaged fluxes were further averaged in time, in 3-h bins, to be consistent with the fluxes inferred from TIC measurements.

Mixed layer heat flux was predominantly negative for the first half of the experiment and closer to zero and/or positive during the second half (Fig. 9a). The average for the entire period was $-0.3 \mathrm{~W} \mathrm{~m}^{-2}$, which indicates a small, downward transfer of heat within the mixed layer and is consistent with the observed downward propagation of the temperature maximum in Fig. 6a. The mixed layer heat flux also showed a shift towards zero and positive values after the snow fall at doy 236.75 and average values were $-0.7 \mathrm{~W} \mathrm{~m}^{-2}$ and $0 \mathrm{~W} \mathrm{~m}^{-2}$ before and after the snowfall, respectively.

The vertical heat flux across the base of the mixed layer was predominantly negative, showing that heat was lost from the mixed layer and into the upper cold halocline. However, average value was small, $-0.1 \mathrm{~W} \mathrm{~m}^{-2}$, with some periods of fluxes close to $-1 \mathrm{~W} \mathrm{~m}^{-2}$.

\section{Discussion}

\subsection{Seasonal evolution in heat and fresh water content}

Throughout the melting season, heat is added to the upper ocean by solar radiation and by exchange with the atmosphere through the sea ice and open water areas. Heat is either stored in the upper ocean or used for melting of sea ice, sensible or latent heat, respectively. The latter is reflected by the FWC in the upper ocean. Thus, when horizontal advection of heat is neglected, the total amount of heat supplied to the upper ocean is equivalent to the sum of sensible and latent heat present at the end of the melting season.

From the profiles of temperature and salinity (Fig. 5), the seasonal evolution of the upper ocean stratification from late April to late August was seen as a reduction in mixed layer depth, an increase in temperature and a decrease in salinity. In late April, the weakly salinity-stratified mixed layer was about $65 \mathrm{~m}$ deep. The presence of a relatively fresh, but shallow surface layer was the signature of the ongoing melting, observed approximately one month following the Arctic ice cover maximum extent was reached in mid-March (National Snow and Ice Data Center, 2010).

The amount of sensible heat added to the upper ocean above $D_{\mathrm{wml}}$ from late April to late August, was $8.6 \times 10^{6} \mathrm{~J} \mathrm{~m}^{-2}$, where $40 \%$ and $60 \%$ were stored in the upper cold halocline and the mixed layer, respectively (Fig. 10). This is in the same order as reported for the Amundsen Basin
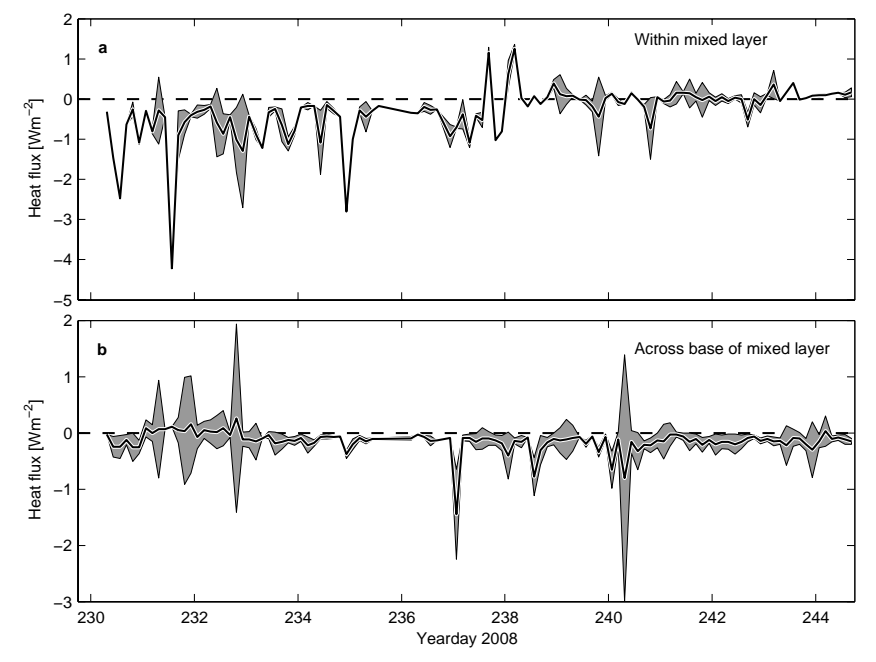

Fig. 9. Time series of heat fluxes averaged (a) within the mixed layer and (b) across the base of the mixed layer. Mixed layer fluxes are depth averages down to $4 \mathrm{~m}$ above the mixed layer depth. Heat fluxes across the base of the mixed layer are depth averages from $4 \mathrm{~m}$ above to $4 \mathrm{~m}$ below mixed layer depth for each profile, averaged into 3 -h intervals. Shading indicates \pm one standard deviation.

from the Oden 91 expedition in the autumn of 1991 (Rudels et al., 1996).

Although sea ice can exist in a mixed layer with a significant amount of heat (e.g. Sirevaag, 2009), the situation in the summer Arctic is assumed to be closer to steady-state. Hence most of the available heat in the mixed layer will be used for melting when ice is present and is thus represented by the FWC in the upper ocean as latent heat, $Q_{\text {lat }}=\rho \cdot L \cdot$ FWC, where $\rho$ and $L$ are the density and latent heat of fusion, respectively. For ASCOS, a FWC of $3.3 \mathrm{~m}$ (of which $91 \%$ resides in the mixed layer and $9 \%$ in the upper cold halocline) was found above $D_{\mathrm{wml}}$, which was more than 3 times larger than the FWC in the Amundsen Basin in 1991 (Rudels et al., 1996). The western part of the Amundsen Basin is likely influenced by the flow of fresh water of Pacific origin across the Lomonosov Ridge, hence FWC estimates above those obtained by Rudels et al. (1996) are expected. However, the estimated FWC in ASCOS also by far exceeds the estimated FWC in profiles obtained closer to the Moris Jesup Plateau in 1991, hence representing a significant freshening of the summer mixed layer in the Eurasian Basin. The total heat content, $Q_{\mathrm{wml}}+Q_{\mathrm{lat}}$, above $D_{\mathrm{wml}}$ at the end of the melting season was $1139 \times 10^{6} \mathrm{~J} \mathrm{~m}^{-2}$ for the ASCOS profile.

Our observations from the Amundsen Basin shows both a significantly fresher summer mixed layer and a significantly saltier winter mixed layer larger than reported from the early 90's (Rudels et al., 1996). The large summer FWC can reflect a general increase in the Arctic fresh water inventory, due to an increasing discharge from Arctic rivers (Peterson et al., 2002; Rawlins et al., 2009) and changes in net precipitation vs. evaporation (Rawlins et al., 2009) over the recent 


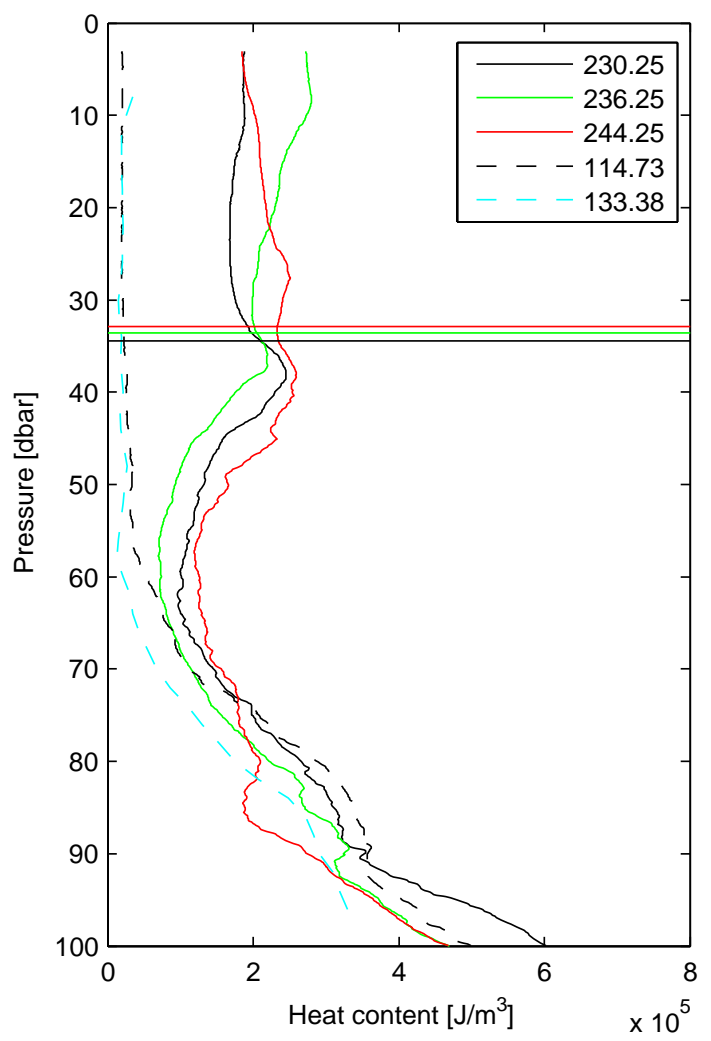

Fig. 10. Heat content of the upper $100 \mathrm{~m}$ for the Barneo08 experiment, the ITP 19 data and at beginning, middle and end of the ASCOS experiment, all profiles obtained as described in Fig. 5. Horizontal lines indicate mixed layer depths for the average profiles.

decade. However, Polyakov et al. (2008) found that changes in both net precipitation vs. evaporation and river discharge were too small to trigger changes in FWC in the central Arctic basin and argued that these changes were related to local freezing/melting and freshwater draining from the Arctic in response to wind. For the western Amundsen Basin, some of the increase in FWC can be exported from the Canadian Basin, where a significant freshening has been observed over the recent years (McPhee et al., 2009; Polyakov et al., 2008). The observed saltier winter mixed layer can reflect an increase in the ice export from the Arctic (Smedsrud et al., 2008), i.e. locally produced ice is exported and melted outside the Arctic. However, the combination of an increase in both FWC and $S_{\mathrm{wml}}$ most likely also indicate a transition towards a more seasonal Arctic ice cover (Kinnard et al., 2008) in the Eurasian Basin. An enhanced fraction of open water after the melting season, increase the ice production during winter, increase the $S_{\mathrm{wml}}$ and hence reduce the winter fresh water content as observed by (McPhee et al., 2009). A shift towards an earlier onset of melting in the Arctic in general (Markus et al., 2009), and even earlier signs of melting reported in this study and by Nicolaus et al. (2010a) for 2007, extends the melting season and increases the summer FWC, as observed.

\subsection{Mixed layer heat content and energy budgets}

In addition to the warming of the mixed layer and upper cold halocline from late April to late August, there was also a distinct variability in heat content during the 15-day ASCOS drift which was reflected in the changing temperature profiles for the start, middle and end of the drift (Fig. 5a). We analysed daily-averaged profiles of heat content in the mixed layer, relative to the first profile, by subtracting the first 24-h profile (centred at doy 230.25) from each subsequent profile and normalising the depth with $D_{\mathrm{ml}}$ (Fig. 11a). Fig. 11b shows that there was a net increase in mixed layer heat content of $30 \%$ up to doy 236.75, which was the time of the freeze-over and snow fall. Heat content profiles also indicate that the initial net input of heat at the top of the mixed layer was mixed downward within the mixed layer. The distinct reduction of heat input at the surface following the freezing event at doy 236.75 also marked a transition after which there was no net gain of heat in the mixed layer, but the heat was redistributed by internal mixing. Despite the reduction in heat input at the surface after doy 236.75 , there was still a temporal variability in the total heat content (Fig. 11b) which can be explained by varying mixed layer depths (e.g. at doy 238 and 241, Fig. 6).

By tracing the depth of the maximum heat content, we estimated the amount of turbulent mixing needed to redistribute the heat. Theoretically, one may consider two layers with uniform temperature separated by a distance $\delta z$. A temperature perturbation introduced in the upper layer will be mixed throughout both layers by turbulence after a time $t$. By assuming that internal turbulent mixing was the only process of redistributing heat, the eddy diffusivity of heat may was estimated as $K_{T}=\frac{\delta z^{2}}{t}$. The depth of the heat content maximum increased from $2.3 \mathrm{~m}$ to $27.6 \mathrm{~m}$ during 10 days from doy 234.25 to 244.25 (Fig. 11b), which gives $K_{T}=$ $3.7 \times 10^{-4} \mathrm{~m}^{2} \mathrm{~s}^{-1}$. In the same depth range and time period, average eddy diffusivity for mass obtained from the MSS measurements (Fig. 6b) was $K_{\rho}=3.8 \times 10^{-4} \mathrm{~m}^{2} \mathrm{~s}^{-1}$, which is identical (within the measurement uncertainty) to the estimate of $K_{T}$ from the downward propagation of the depth of maximum heat content. This lends confidence on invoking the Reynolds analogy for the Arctic mixed layer, equating the eddy diffusivity of heat and mass.

The periods with elevated levels of dissipation rate and eddy diffusivity in the upper ocean around doy 233, 238 and 242 (Fig. 6b) coincided with periods of increased drift speed (Fig. 3c) and increased stress in the upper ocean (Fig. 7b) and indicates that mixing was mostly driven by wind and tides. Dissipation rate estimates from MSS and TIC at $7.8 \mathrm{~m}$ depth (Fig. 6c) agreed very well, which lends confidence to the MSS measurements in the upper ocean in general.

The overall average transmittance of solar radiation was 0.024 , which means that $2.4 \%$ of the incident solar radiation $\left(106 \mathrm{~W} \mathrm{~m}^{-2}\right)$ was transmitted through the ice/snow pack 

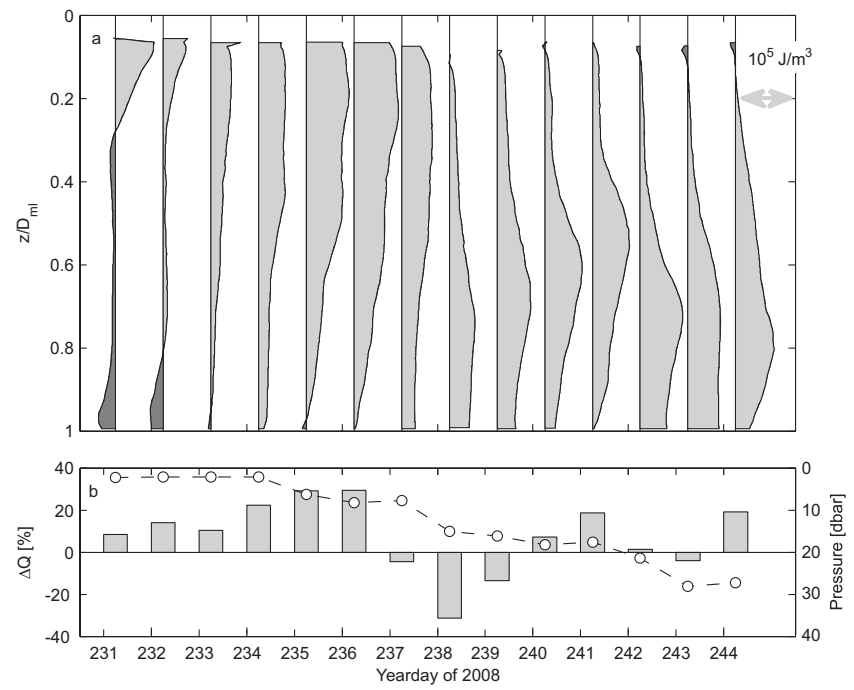

Fig. 11. (a) Difference in heat content $\left(\mathrm{J} \mathrm{m}^{-3}\right)$ for subsequent $24-\mathrm{h}$ averaged profiles relative to the first profile centred at 230.25. Depth is normalized by the mixed layer depth for each profile. Light gray shading indicates heat gained from the first profile and dark gray shading indicates heat lost from the first profile. (b) Change in total mixed layer heat content for average profiles relative to the first profile (bars) and the pressure ( $\sim$ depth) at heat content maximum, vertical axis on the right (circles).

(ice thickness $1.5 \mathrm{~m}$, snow thickness $0.1 \mathrm{~m}$ ) and into the upper ocean. The freezing and snow fall at doy 236.75 did not only increase the surface albedo from 0.86 to 0.92 but also reduced the transmittance from 0.030 to 0.015 (see also Nicolaus et al., 2010b), which means that twice as much of the incoming solar radiation was reflected or absorbed within the ice. A similar doubling of reflection and absorption was observed in a comparable time of freezeup during the drift of the schooner Tara (Nicolaus et al., 2010a). The estimated transmittance is slightly smaller than previous estimates by Perovich (2005) for bare ice (8\%) and by Light et al. (2008) for melting ice ( $3 \%$ for $3 \mathrm{~m}$ thick ice, $15 \%$ for $1 \mathrm{~m}$ thick ice), however the difference can be attributed to the snow cover of the ASCOS ice floe.

The classic thermodynamic ice/ocean model of Maykut and Untersteiner (1971) assumes a constant ocean heat flux of $2 \mathrm{~W} \mathrm{~m}^{-2}$ to reach an equilibrium ice thickness, although later studies have shown that the ocean heat flux has a large spatial (e.g. Krishfield and Perovich, 2005) and temporal variability (e.g. Maykut and McPhee, 1995) throughout the Arctic. Average surface ocean heat flux during ASCOS $\left(1.2 \mathrm{~W} \mathrm{~m}^{-2}\right)$ was slightly less than $2 \mathrm{~W} \mathrm{~m}^{-2}$, but comparable. The relatively small ocean heat flux reflects the modest turbulent mixing (as manifested by the friction velocity) and amount of heat that was available in the mixed layer, where the slowly decaying $u_{*}$ towards the end of the drift partly explains why the ocean heat flux approached zero.
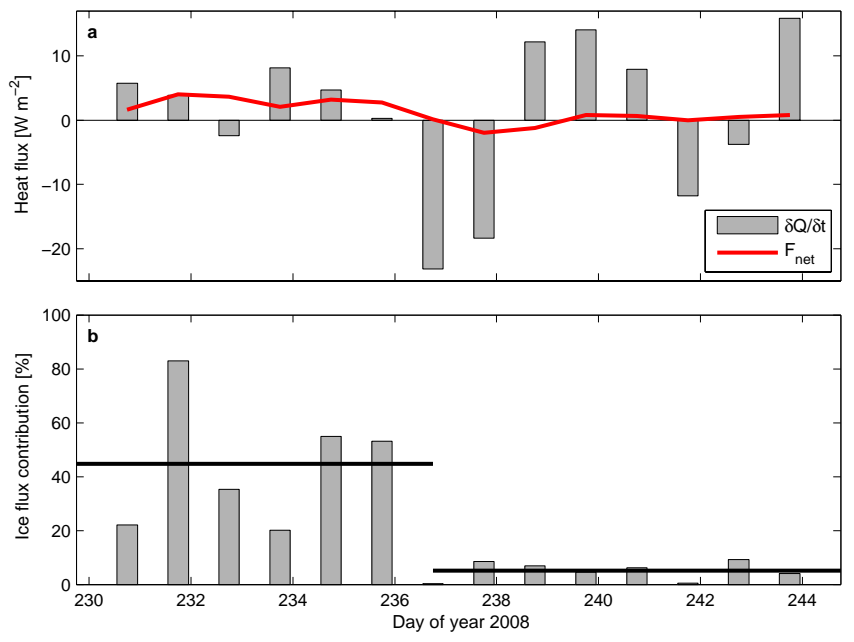

Fig. 12. (a) Change in total mixed layer heat content within consecutive 24-h intervals (bars) and net vertical heat fluxes into the mixed layer (thick line). (b) Contribution of net ice fluxes to the total change in mixed layer heat content. Horizontal lines are averages for the two periods before and after doy 236.75 .

At the base of the mixed layer, there was a small, downward flux of heat into the upper cold halocline. To add the heat stored in the upper cold halocline from Borneo08 to ASCOS (Fig. 10), would require an average heat flux of $-0.35 \mathrm{~W} \mathrm{~m}^{-2}$, which is roughly 2 times the magnitude of the observed flux across the base of the mixed layer, $-0.14 \mathrm{~W} \mathrm{~m}^{-2}$ (Fig. 9b). Although these values were small and not significantly different from zero, one would expect that the heat transfer was more efficient at the start of the melting season, before the strong stratification of the cold halocline was properly established. The heat flux from below $D_{\mathrm{wml}}$, in the depth range $60-68 \mathrm{~m}$, was negligible (not shown), hence all of the heat in the upper cold halocline was most likely supplied from the mixed layer.

Neglecting any spatial variability in mixed layer heat content, any observed change between subsequent 24-h intervals (Fig. 11), reflects a net heat flux into or out of the mixed layer during these periods. This net heat flux is a sum of fluxes through the ice and open water minus the heat flux leaving the ocean through the surface and through the base of the mixed layer. The ice cover is variable and spatially nonhomogeneous, ranging from very thin to thick multi-year ice with variable melt pond fractions and snow cover, modifying the heat exchange between the ocean and the atmosphere accordingly. Each of these variations in ice cover will have its own steady state heat flux balance with the ocean mixed layer, hence an observed change in mixed layer heat content will be the integrated effect of the surface conditions the mixed layer "experiences" during a 24-h period.

The net heat flux through the ice cover was calculated as the sum of the transmitted solar radiation, surface ocean heat flux and heat flux across the base of the mixed layer for 24-h 
periods and plotted together with the change in mixed layer heat content (Fig. 12a). Before doy 236.75, net heat fluxes through the ice were of the same order as the change in mixed layer heat content, although this was in general larger in magnitude. After the freezing and snow fall at doy 236.75, changes in heat content were larger, more variable and the net heat flux through the ice was almost negligible, hence it indicates that the ice was not the main passageway for transfer of heat between the atmosphere and the upper ocean in this period.

For simplicity, we assume three categories of ocean surface; ice, open water or melt pond, which all represent different set of net heat fluxes into the ocean mixed layer. The resulting change in mixed layer heat content was calculated as

$\Delta H_{\mathrm{ml}} / \Delta t=F_{\text {net }} \alpha_{i}+F_{\mathrm{ow}} \alpha_{\mathrm{ow}}$

where $F_{\text {net }}, F_{\text {ow }}$ and $F_{\mathrm{mp}}$ are the net heat flux balance for ice, open water and melt ponds respectively and $\alpha_{i}, \alpha_{\text {ow }}$ and $\alpha_{\text {mp }}$ are the area fraction of ice, open water and melt ponds. From our observations, we have relatively high temporal resolution in $F_{\text {net }}$ and $\Delta Q_{\mathrm{ml}}$ and will in the following focus on the contribution from the heat exchange through the ice to the change in mixed layer heat content.

To estimate the area fraction of ice, a series of 13 aerial photos of the area was digitally converted and analysed to obtain the ratio of ice and open water. All images were taken during the ASCOS drift at heights of $600-1300 \mathrm{~m}$ and covered areas of roughly $6 \times 4 \mathrm{~km}$ to $12 \times 9 \mathrm{~km}$, centred around Oden. The analysis provided $\alpha_{i}=0.8$.

The fractional contribution of the net ice fluxes to the change in mixed layer heat content (Fig. 12b) was significant during the first period, where it accounted for $45 \%$ of the observed change in heat content, however it dropped to $5 \%$ for the second period. This showed the impact of the snow cover and freezing of the surface for isolating the upper ocean from exchange with the atmosphere, but also reflected a larger variability in the heat content change. Overall, net ice fluxes accounted for $22 \%$ of the change in heat content which is similar to the $23 \%$ obtained by the $1997 / 1998$ SHEBA campaign (Perovich, 2005), but higher than the $12 \%$ estimate based on the 1975 AIDJEX experiment (Maykut and McPhee, 1995).

On average, heat exchange through open water and melt ponds accounted for $78 \%$ of the change in mixed layer heat content. Since we do not know $F_{\mathrm{ow}}$ and $F_{\mathrm{mp}}$ (Eq. 7), we are not able to distinguish the importance of open water vs. melt ponds. However, the melt pond coverage was quite small and our image analysis indicated melt pond fractions below $5 \%$ both before and after doy 236.75. Hence, exchange of heat through open water seemed to be most important for heating of the ocean mixed layer during ASCOS.

Estimate of the fractional contribution of net ice fluxes is limited by the assumption that $\alpha_{i}=0.8$, i.e. $80 \%$ of the area have the same ice and snow properties as found at the experiment site, and that no melting/freezing was taken into account at the ice/ocean interface. The experiment floe was the largest found in the area and also had more dominant surface structures than smaller, surrounding floes, which would accumulate more snow. Hence one could expect that the transfer of heat through the ice would be larger for the surrounding floes and our estimate is in that sense a low estimate.

We assumed that there was little melting at the bottom of the ice cover during ASCOS. Repeated ice thickness measurements could not reveal any significant change in ice thickness and measured salt fluxes at $3.8 \mathrm{~m}$ depth (not shown) were also small and actually indicated a net freezing at the surface. Also, we have included the ocean heat flux at the interface in the net ice fluxes, hence the heat is already "leaving" the ocean mixed layer, irrespective of whether it goes to melting at the interface or to conduction through the ice.

\subsection{Heat content and heat flux variability}

Despite the reduction in heat input at the surface, the changes in heat content in the period following the change in surface conditions at doy 236.75 were significant. The magnitudes of changes in mixed layer heat content (Fig. 12) were even larger than prior to doy 236.75. In Fig. 13, the standard deviation of heat content is shown, averaged in depth bins of $1 \mathrm{~m}$ and in periods before and after doy 236.75. The variability in heat content was larger in the upper $25 \mathrm{~m}$ of the mixed layer before doy 236.75, when there was transfer of heat through the ice and larger areas of open water/leads. In the period after doy 236.75 , the largest variability was found below $25 \mathrm{~m}$, indicating a horizontal variability of mixed layer heat content which was not related to surface forcing, but to heat that was transferred into the mixed layer and mixed downwards at an earlier stage. To investigate the impact of the altered surface conditions, the average change in heat content for the upper $25 \mathrm{~m}$ and surface ocean heat flux were grouped according to the direction of the mean flow, separating flow from underneath the large ice floe and flow from the area with open leads and smaller ice floes (lower left corner in Fig. 2), (Fig. 14). Before doy 236.75, a flow of water from the area with open water lead to an increase in heat content, most likely due to the absorbed short wave radiation that previously took place through the open water. Although flow from under the ice floe also indicated a net increase of heat, there was only one 3 -h interval satisfying these conditions before doy 236.75 , hence this result was not considered here. After the change in surface conditions, both flow from the open water and from underneath the ice floe lead to reduced heat content in the upper $20 \mathrm{~m}$. This indicates that there was a change in surface forcing under both types of conditions and that there was a net cooling of the surface instead of heating. For the ice covered area, this was achieved by blocking the incoming short wave radiation from penetrating into the upper ocean and by increasing the conductive transfer of heat towards the 


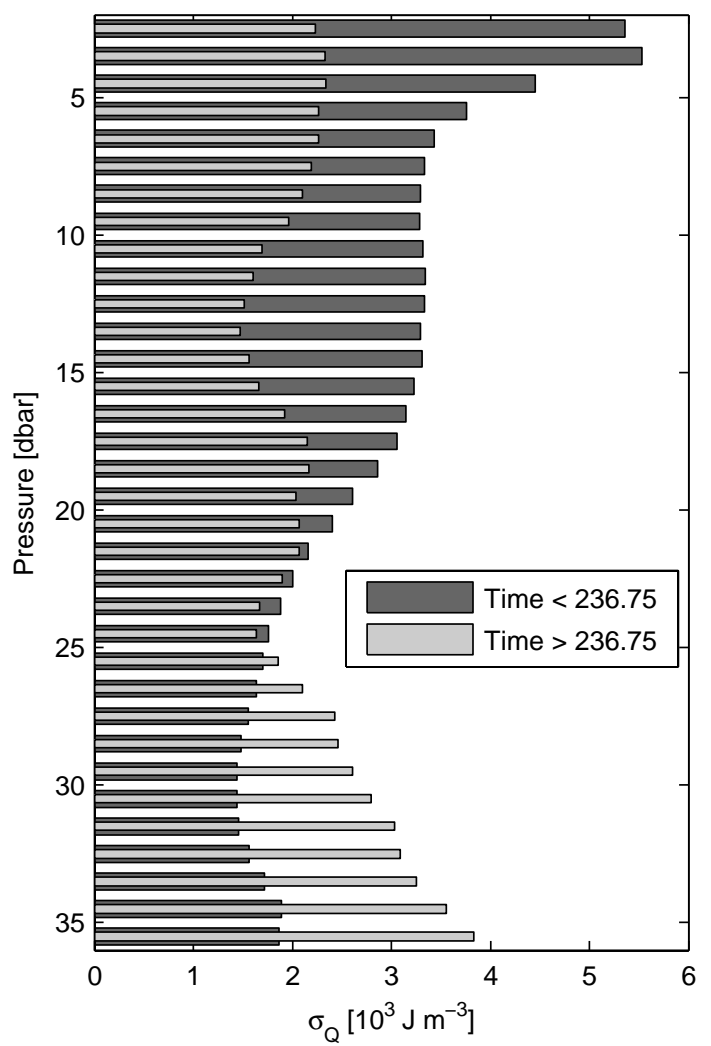

Fig. 13. Average standard deviation of heat content in depth bins for the periods before and after doy 236.75 .

ice surface, driven by a decreasing air temperature. For the open water areas, the freezing leads to reduced input of radiation to the upper ocean and a stronger conductive cooling through the thin ice, also driven by the lower air temperature.

The observed changes in net energy balance at the surface was not only a result of the changing surface conditions with the freezing and snow cover, but also a result of a gradual shift in surface energy balance in a transition from melting to freezing. During the same ASCOS drift, Sedlar et al. (2010) analysed the energy balance at the ice surface and found that the net energy balance shifted from positive (heating of the surface) to negative (cooling of the surface) towards the end of the drift (doy 243), driven by a net deficit of long wave radiation and a decrease in net short wave radiation. For the thin ice over the leads, the cooling will be stronger due to a larger conductive flux through the thin ice than through the thicker ice. The ocean heat flux remained positive during the entire drift (Sect. 3.2) and increased slightly after doy 236.75 for both water flowing from the open water areas and from underneath the ice floe. This was caused by a reduced temperature gradient (larger negative gradient) in the upper $20 \mathrm{~m}$ (not shown), set up by a stronger surface cooling from both source regions, which enhanced the turbulent heat flux towards the ice/ocean interface.

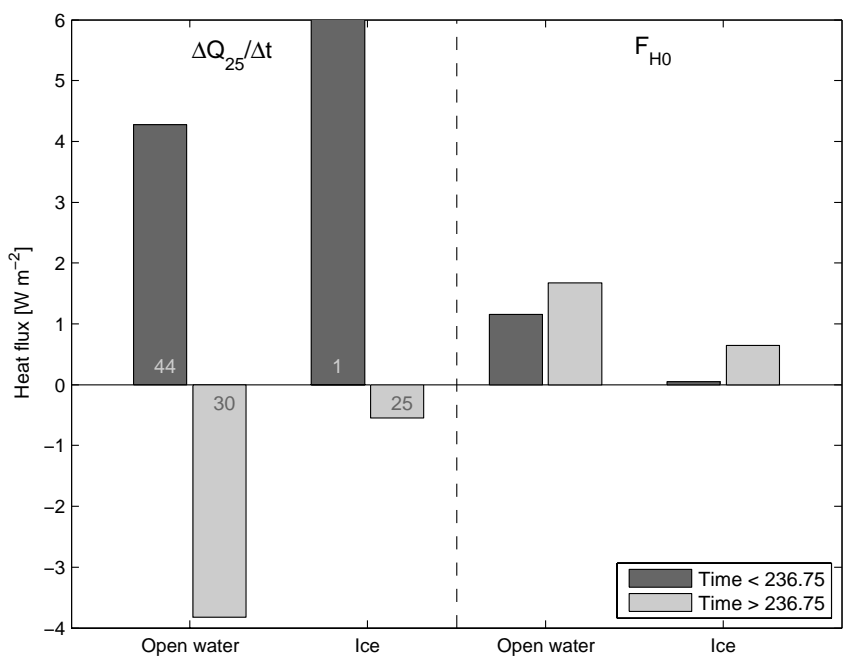

Fig. 14. (a) Change in heat content $\left(\Delta H_{20} / \Delta t\right)$ in the upper $20 \mathrm{~m}$ and (b) ocean heat flux $\left(F_{H 0}\right)$ averaged according to flow direction and period before and after doy 236.75. Change in heat content was calculated within 3-h intervals and the average current direction within the same period was used to classify the flow from the mostly open water covered area or the flow from the ice covered area. Numbers on the $\Delta H_{20} / \Delta t$ bars indicate the number of 3-h intervals that were averaged. $\Delta H_{20} / \Delta t$ from the ice before doy 236.75 extends outside the axis with a value equal to $10 \mathrm{~W} \mathrm{~m}^{-2}$, but was discarded since it contained only one 3-h interval.

\section{Summary}

As part of the multidisciplinary Arctic Summer Cloud Ocean Study (ASCOS) in 2008, a comprehensive upper ocean measurement program was performed during a 16-days long drifting ice station centred at $87.5^{\circ} \mathrm{N}$ and $5^{\circ} \mathrm{E}$. During the drift, which lasted from 15 August to 1 September, high resolution sampling of ocean stratification, turbulent mixing and exchange in the upper $500 \mathrm{~m}$ were made in addition to measurements of short wave radiation at the ice surface and below the $1.8 \mathrm{~m}$ thick ice. The measurements show the development of the upper ocean stratification, heat content, and iceocean-atmosphere interaction in the transition period from the end of the melting season to the initialization of the freezing season.

A comparison of the ASCOS data with CTD data from an experiment in the same area in late April 2008 and to data from an Ice Tethered Profiler (ITP19) which drifted through the area in mid May 2008, showed that the ocean mixed layer decreased in thickness, from $67 \mathrm{~m}$ to $34 \mathrm{~m}$ due to a supply of fresh water from melting of sea ice. Until the end of August, a total of $1139 \times 10^{6} \mathrm{~J} \mathrm{~m}^{-2}$ was added to the mixed layer and upper cold halocline, where $8.1 \times 10^{6} \mathrm{~J} \mathrm{~m}^{-2}$ was present as sensible heat and the latent heat was represented by a fresh water equivalent of $3.3 \mathrm{~m}$. The total amount of heat was more than 3 times the observed heat in the early 1990's and the fresh water content also represents a significant freshening 
of the upper ocean in this area. The salinity of the winter mixed layer was found to be higher than previously measured, which, together with the increase in fresh water content, represents a transition towards a more seasonal ice cover with a more pronounced freezing and melting cycle.

Average heat fluxes over the period of the ASCOS drift were found to be $1.2 \mathrm{~W} \mathrm{~m}^{-2},-0.3 \mathrm{~W} \mathrm{~m}^{-2}$ and $-0.1 \mathrm{~W} \mathrm{~m}^{-2}$ for the ice/ocean interface, internally in the mixed layer and across the base of the mixed layer, respectively, showing that heat was transferred from the mixed layer and into the upper cold halocline. The heat flux across the base of the mixed layer was of the same order as necessary to accumulate the observed heat in the upper cold halocline by the end of the melting season.

Mean solar radiation transmitted through the sea ice was found to be $-2.6 \mathrm{~W} \mathrm{~m}^{-2}$, which contributed to a warming of the ocean mixed layer. However, the change in surface conditions by the snow fall reduced the average flux from the first to the second half of the experiment from $-3.7 \mathrm{~W} \mathrm{~m}^{-2}$ to $-1.5 \mathrm{~W} \mathrm{~m}^{-2}$, respectively.

The ocean mixed layer was found to be heated from the top and heat was redistributed downwards by turbulent mixing. By comparing the changing heat content of the mixed layer and net fluxes into the mixed layer, it was found that the exchange of heat through the ice cover accounted for $22 \%$ of the change in mixed layer heat content, with main contribution from transmittance of solar radiation through the ice. For the first part of the drift, net fluxes through the ice accounted for $45 \%$ of the change in heat content, which increased by $30 \%$ in the same period. Midway in the drift, a cold period followed by a snow fall changed the surface conditions significantly. Very little heat was added from the top of the ocean mixed layer and heat was redistributed internally. By tracking the depth of the maximum heat content, an eddy diffusivity of heat was estimated to $3.7 \times 10^{-4} \mathrm{~m}^{2} \mathrm{~s}^{-1}$, identical to the measured eddy diffusivity of mass. Significant variability in heat content was seen in the second period; however the variability was largest in the lower half of the mixed layer, which reflected the variability in heat previously transferred to the upper ocean and changes in mixed layer depth.

This paper reveals the importance of the transfer of energy through the ice cover for the heat content of the Arctic mixed layer and gives insight into some of the processes at play in the upper Arctic Ocean, which bears the signatures of an ice cover in transition towards being more seasonal. Besides showing the upper ocean development towards the end of the melting season, it also illustrates the variability caused by changing surface conditions over relatively short spatial scales, which are processes that need to be investigated further in future studies.
Acknowledgements. This work is part of ASCOS (the Arctic Summer Cloud Ocean Study) and was funded by the Bjerknes Center for Climate Research and the NorClim project, funded by Norwegian Research council. ASCOS was made possible by funding from the Knut and Alice Wallenberg Foundation and the DAMOCLES European Union 6th Framework Program Integrated Research Project. The Swedish Polar Research Secretariat (SPRS) provided access to the icebreaker Oden and logistical support. Caroline Leck and Michael Tjernström were Chief Scientists and responsible for planning and coordination of ASCOS. We are grateful to the SPRS logistical staff and to Oden's Captain Mattias Peterson and his crew. We also thank Caroline Leck for useful comments on the manuscript. ASCOS is an IPY project under the AICIA-IPY umbrella and an endorsed SOLAS project. The Ice-Tethered Profiler data were collected and made available by the Ice-Tethered Profiler Program based at the Woods Hole Oceanographic Institution (http://www.whoi.edu/itp). The optical instrumentation was kindly provided by Norwegian Polar Institute (Sebastian Gerland). This is publication number A328 from the Bjerknes Center for Climate Research.

Edited by: I. Brooks

\section{References}

Aagaard, K., Coachman, L. K., and Carmack, E.: On the halocline of the Arctic Ocean, Deep-Sea Res., 28, 529-545, 1981.

Alkire, M. B., Falkner, K. K., Rigor, I., Steele, M., and Morison, J.: The return of Pacific waters to the upper layers of the central Arctic Ocean, Deep-Sea Res. Pt. I, 54, 1509-1529, doi:10.1016/j.dsr.2007.06.004, 2007.

Comiso, J. C.: Warming trends in the Arctic from clear sky satellite observations, J. Climate, 16, 3498-3510, 2003.

Comiso, J. C., Parkinson, C. L., Gersten, R., and Stock, L.: Accelerated decline in the Arctic Sea ice cover, Geophys. Res. Lett., 35, doi:10.1029/2007g1031972, 2008.

Dillon, T. M. and Caldwell, D. R.: The Batchelor spectrum and dissipation in the upper ocean, J. Geophys. Res.-Oceans, 85, 19101916, 1980.

Dmitrenko, I. A., Polyakov, I. V., Kirillov, S. A., Timokhov, L. A., Frolov, I. E., Sokolov, V. T., Simmons, H. L., Ivanov, V. V., and Walsh, D.: Toward a warmer Arctic Ocean: Spreading of the early 21 st century Atlantic Water warm anomaly along the Eurasian Basin margins, J. Geophys. Res.-Oceans, 113, doi:10.1029/2007jc004158, 2008.

Fer, I.: Scaling turbulent dissipation in an Arctic fjord, Deep-Sea Res. Pt. II, 53, 77-95, 2006.

Fer, I. and Sundfjord, A.: Observations of upper ocean boundary layer dynamics in the marginal ice zone, J. Geophys. Res.Oceans, 112, C04012, doi:10.1029/2005JC003428, 2007.

Fer, I.: Weak vertical diffusion allows maintenance of cold halocline in the central Arctic, Atmospheric and Oceanic Science Letters, 2, 148-152, 2009.

Grotefendt, K., Logemann, K., Quadfasel, D., and Ronski, S.: Is the Arctic Ocean warming?, J. Geophys. Res.-Oceans, 103, 2767927687, 1998.

Haas, C., Pfaffling, A., Hendricks, S., Rabenstein, L., Etienne, J. L., and Rigor, I.: Reduced ice thickness in Arctic Trans- 
polar Drift favors rapid ice retreat, Geophys. Res. Lett., 35, doi:10.1029/2008g1034457, 2008.

Inoue, J., Kikuchi, T., and Perovich, D. K.: Effect of heat transmission through melt ponds and ice on melting during summer in the Arctic Ocean, J. Geophys. Res.-Oceans, 113, doi:10.1029/2007jc004182, 2008.

Itoh, M., Inoue, J., Shimada, K., Zimmermann, S., Kikuchi, T., Hutchings, J., McLaughlin, F., and Carmack, E.: Acceleration of sea-ice melting due to transmission of solar radiation through ponded ice area in the Arctic Ocean: results of in situ observations from icebreakers in 2006 and 2007, Ann. Glaciol., 52, 249-260, 2011.

Kinnard, C., Zdanowicz, C. M., Koerner, R. M., and Fisher, D. A.: A changing Arctic seasonal ice zone: Observations from 18702003 and possible oceanographic consequences, Geophys. Res. Lett., 35, doi:10.1029/2007g1032507, 2008.

Krishfield, R. A. and Perovich, D. K.: Spatial and temporal variability of oceanic heat flux to the Arctic ice pack, J. Geophys. Res.-Oceans, 110, C07021, doi:10.1029/2004JC002293, 2005.

Kwok, R., and Rothrock, D. A.: Decline in Arctic sea ice thickness from submarine and ICESat records: 1958-2008, Geophys. Res. Lett., 36, doi:10.1029/2009g1039035, 2009.

Light, B., Grenfell, T. C., and Perovich, D. K.: Transmission and absorption of solar radiation by Arctic sea ice during the melt season, J. Geophys. Res.-Oceans, 113, doi:10.1029/2006jc003977, 2008.

National Snow and Ice Data Center: http://nsidc.org/ arcticseaicenews/2008/040708.html, last access: 20 October 2010, 2010.

Markus, T., Stroeve, J. C., and Miller, J.: Recent changes in Arctic sea ice melt onset, freezeup, and melt season length, J. Geophys. Res.-Oceans, 114, doi:10.1029/2009jc005436, 2009.

Maslanik, J. A., Fowler, C., Stroeve, J., Drobot, S., Zwally, J., Yi, D., and Emery, W.: A younger, thinner Arctic ice cover: Increased potential for rapid, extensive sea-ice loss, Geophys. Res. Lett., 34, doi:10.1029/2007GL032043, 2007.

Maykut, G. A. and Untersteiner, N.: Some Results from a TimeDependent Thermodynamic Model of Sea Ice, J. Geophys. Res., 76, 1550-1575, 1971.

Maykut, G. A. and McPhee, M. G.: Solar heating of the Arctic mixed layer, J. Geophys. Res.-Oceans, 100, 24691-24703, 1995.

McPhee, M. G.: A spectral technique for estimating turbulent stress, scalar flux magnitude, and eddy viscosity in the ocean boundary layer under pack ice, J. Phys. Oceanogr., 34, 2180-2188, 2004.

McPhee, M. G.: Air-Ice-Ocean interaction: Turbulent Boundary Layer Exchange Processes, Springer, New York, 215 pp., 2008.

McPhee, M. G., Proshutinsky, A., Morison, J. H., Steele, M., and Alkire, M. B.: Rapid change in freshwater content of the Arctic Ocean, Geophys. Res. Lett., 36, doi:10.1029/2009g1037525, 2009

Nghiem, S. V., Rigor, I. G., Perovich, D. K., ClementeColon, P., Weatherly, J. W., and Neumann, G.: Rapid reduction of Arctic perennial sea ice, Geophys. Res. Lett., 34, doi:10.1029/2007GL031138, 2007.

Nicolaus, M., Gerland, S., Hudson, S. R., Hanson, S., Haapala, J., and Perovich, D. K.: Seasonality of spectral albedo and transmittance as observed in the Arctic Transpolar Drift in 2007, J. Geophys. Res., 115, C11011, doi:10.1029/2009jc006074, 2010a.
Nicolaus, M., Hudson, S. R., Gerland, S., and Munderloh, K.: A modern concept for autonomous and continuous measurements of spectral albedo and transmittance of sea ice, Cold Regions Science And Technology, 62, 14-28, doi:10.1016/j.coldregions.2010.03.001, 2010b.

Niebauer, H. J. and Alexander, V.: Oceanographic frontal structure and biological production at an ice edge, Cont. Shelf Res., 4, 367-388, 1985.

Osborn, T. R. and Cox, C. S.: Oceanic fine structure, Geophys. Fluid Dyn., 3, 321-345, 1972.

Osborn, T. R.: Estimates of the Local Rate of Vertical Diffusion from Dissipation Measurements, J. Phys. Oceanogr., 10, 83-89, 1980.

Padman, L.: Small-scale physical processes in the Arctic Ocean, in: Arctic Oceanography: Marginal Ice Zones and Continental Shelves, edited by: Smith, W. O. and Grebmeier, J., AGU, Washington D.C., 1995.

Parkinson, C. L. and Cavalieri, D. J.: Arctic sea ice variability and trends, 1979-2006, J. Geophys. Res.-Oceans, 113, doi:10.1029/2007jc004558, 2008.

Perovich, D. K.: On the aggregate-scale partitioning of solar radiation in Arctic sea ice during the Surface Heat Budget of the Arctic Ocean (SHEBA) field experiment, J. Geophys. Res.-Oceans, 110, doi:10.1029/2004jc002512, 2005.

Peterson, B. J., Holmes, R. M., McClelland, J. W., Vorosmarty, C. J., Lammers, R. B., Shiklomanov, A. I., Shiklomanov, I. A., and Rahmstorf, S.: Increasing river discharge to the Arctic Ocean, Science, 298, 2171-2173, 2002.

Polyakov, I. V., Alexeev, V. A., Belchansky, G. I., Dmitrenko, I. A., Ivanov, V. V., Kirillov, S. A., Korablev, A. A., Steele, M., Timokhov, L. A., and Yashayaev, I.: Arctic ocean freshwater changes over the past 100 years and their causes, J. Climate, 21, 364-384, doi:10.1175/2007jcli1748.1, 2008.

Rainville, L. and Woodgate, R. A.: Observations of internal wave generation in the seasonally ice-free Arctic, Geophys. Res. Lett., 36, doi:10.1029/2009g1041291, 2009.

Rawlins, M. A., Serreze, M. C., Schroeder, R., Zhang, X. D., and McDonald, K. C.: Diagnosis of the record discharge of Arctic-draining Eurasian rivers in 2007, Environ. Res. Lett., 4, doi:10.1088/1748-9326/4/4/045011, 2009.

Rudels, B., Anderson, L. G., and Jones, E. P.: Formation and evolution of the surface mixed layer and halocline of the Arctic Ocean, J. Geophys. Res.-Oceans, 101, 8807-8821, 1996.

Rudels, B., Meyer, R., Fahrbach, E., Ivanov, V. V., Østerhus, S., Quadfasel, D., Schauer, U., Tverberg, V., and Woodgate, R. A.: Water mass distribution in Fram Strait and over the Yermak Plateau in summer 1997, Annales Geophysicae-Atmospheres Hydrospheres and Space Sciences, 18, 687-705, 2000.

Screen, J. A. and Simmonds, I.: The central role of diminishing sea ice in recent Arctic temperature amplification, Nature, 464, 1334-1337, doi:10.1038/nature09051, 2010.

Sedlar, J., Tjernström, M., Mauritsen, T., Shupe, M. D., Brooks, I. M., Persson, O. G., Birch, C. E., Leck, C., Sirevaag, A., and Nicolaus, M.: A transitioning Arctic surface energy budget: The impacts of solar zenith angle, surface albedo and cloud radiative forcing, submitted to Clim. Dynam., 2010.

Serreze, M. C., Barrett, A. P., Stroeve, J. C., Kindig, D. N., and Holland, M. M.: The emergence of surface-based Arctic amplification, Cryosphere, 3, 11-19, 2009. 
Shaw, W. J., Stanton, T. P., McPhee, M. G., Morison, J. H., and Martinson, D. G.: Role of the upper ocean in the energy budget of Arctic sea ice during SHEBA, J. Geophys. Res.-Oceans, 114, doi:10.1029/2008jc004991, 2009.

Sirevaag, A.: Turbulent exchange coefficients for the ice/ocean interface in case of rapid melting, Geophys. Res. Lett., 36, doi:10.1029/2008GL036587, 2009.

Sirevaag, A. and Fer, I.: Early Spring Oceanic Heat Fluxes and Mixing Observed from Drift Stations North of Svalbard, J. Phys. Oceanogr., 39, 3049-3069, doi:10.1175/2009jpo4172.1, 2009.
Smedsrud, L. H., Sorteberg, A., and Kloster, K.: Recent and future changes of the Arctic sea-ice cover, Geophys. Res. Lett., 35, doi:10.1029/2008g1034813, 2008.

Stroeve, J., Serreze, M., Drobot, S., Gearheard, S., Holland, M. M., Maslanik, J., Meier, W., and Scambos, T.: Arctic Sea Ice Extent Plummets in 2007, Eos Trans. AGU, 89, doi:10.1029/2008EO020001, 2008.

Woodgate, R. A., Weingartner, T., and Lindsay, R.: The 2007 Bering Strait oceanic heat flux and anomalous Arctic sea-ice retreat, Geophys. Res. Lett., 37, doi:10.1029/2009g1041621, 2010. 